\title{
SOSIALISASI "SWIMCARD" UNTUK MENINGKATKAN DAYA TANGKAP SERTA KEMAMPUAN GERAK SISWA SLB
}

\author{
Bhayu Billiandri, Ipang Setiawan, Martin Sudarmono, dan Auli Nur Prasasti \\ Jurusan Pendidikan Jasmani Kesehatan dan Rekreasi, Fakultas Ilmu Keolahragaan, \\ Universitas Negeri Semarang \\ E-mail : bhayubilliandri@mail.unnes.ac.id
}

\begin{abstract}
ABSTRAK
Media swimcard merupakan perantara dalam proses pembelajaran yang digunakan untuk meningkatkan kemampuan kognitif serta psikomotorik siswa SLB. Metode pelaksanaan pengabdian ini dilakukan dengan berproses pada empat macam, yaitu membuat planning, melakukan tindakan, mengobservasi dan menilai serta merefleksi. Hasil pengabdian di slb surya bunda adalah berhasil, terbukti dilihat dari kemampuan sebelum dan kemampuan sesudah di tes setelah mendapatkan sosialisasi swimcard renang gaya bebas. Peningkatan kemampuan kognitif dirangsang oleh media bergambar yang menstimulus siswa untuk lebih mengetahu gerakan renang gaya bebas yang baik dan benar. Program pengabdian kepada masyarakat di slb hendaknya kita tingkatkan, terbukti dengan dilaksanakannya program sosialisasi swimcard di slb surya bunda mempunyai efek yang positif, sebagai berikut, Siswa menjadi lebih antusias dalam belajar pendidikan jasmani terutama materi aktifitas air(renang gaya bebas), Siswa lebih menguasai pemahaman gaya bebas dari segi teknik gerakannya, Terobosan inovasi swimcard menjadikan nilai lebih dalam siswa belajar, Sebelum terjun kea rah praktek gerakan siswa akan lebih mengetahui arah dan tujuan gerak yang ingin atau akan dicapai, Sebagai usaha peningkatan literasi pendidikan jasmani di sekolah.
\end{abstract}

\section{Kata Kunci : Swimcard, Media, Kognitif, Psikomotorik, Siswa Luar Biasa}

\section{PENDAHULUAN}

Sekolah merupakan tempat untuk mencerdaskan dan memberikan bekal yang cukup untuk siswa belajar mengenal lingkungan social. Kesempatan untuk pengembangan diri juga salah satunya terdapat disekolah, mata pelajaran menjadi spesifikasi peminatan dan juga bakat bagi siswa, ada yang menyukai pelajaran eksak, social, aktifitas fisik dan lain sebagainya (Arifin, 2013). Berbagai ragam dan maca serta corak siswa dan guru berada pada satu sekolah yang senantiasa menantikan harapan, karena di manapun pijakan cita-cita banyak dimulai dari bangku sekolah (Fathur Rahman dkk, 2020).

Mata pelajaran pendidikan jasmani terdiri dari berbagai macam serta model dalam pelaksannannya, domain kognitif, afektif dan psikomotor menjadi bidang garapan dari mata pelajaran ini (Rosnawati, 2005). Renang menjadi salah satu dari sekian banyak pelajaran yang ada di kurikulun sekolah, aktivitas dan kegiatan air tentunya menjadi pembeda, 
sehingga siswa akan merasa antusias (Kurnia dan Astuti, 2017). Didalam pelaksanaanya renang/aktivitas air terdapat beberapa materi yang diajarkan diantaranya adalah pengenalan air, latihan meluncur dan latihan gerak gaya diantara gaya crawl, kupu-kupu, punggung dan dada (Eager, 2014).

Kendala yang dihadapi dalam pembelajaran sering dijumpai, sarana dan prasarana menjadi unsur pokok yang wajib dipenuhi dalam pemenuhan kebutuhan pembelajaran. Banyak siswa dan siswa tidak bisa melaksanakan aktifitas ii karena beberapa kendala yang terjadi, diantaranya adalah jarak yang jauh, tidak adanya ases atau transportasi umum yang memadai hingga mahalnya tiket masuk (Rosnawati, 2005), bisa dibayangkan anak sekolah usia itu yang notabene ingin menyalurkan segala macam dan ragam aktifitasnya tetapi terkendala dengan sarana dan prasarana, sungguh menyedihkan. Oleh sebab itu penulis inggin menjadi masalah ini mulai dapat teratasi dengan adanya media pembelajaran yang nantinya akan berguna untuk penguatan kognitif serta berpengaruh ke psikomotorik siswa (Leila dkk, 2020). Kartu renang dipilih karena disesuaikan dengan umur siswa yang akan diberikan stimulus, dengan harapan sambal bermain tetapi mendapatkan mafaat dari apa yang dilakukan (Bramantha, 2017).

Dalam beberapa kesempatan saat observasi, penulis mendapati beberapa kendala yang dihadapi dalam pembelajaran renang. Diantaranya adalah sebabgai berikut:

1. Sarana dan prasarana untuk pembelajaran renang yang mahal

2. Tiket yang mahal untuk masuk ke kolam renang

3. Kolam renang tidak representative untuk pembelajaran renang

4. Kesulitan ases dalam perjalanan ke kolam renang

5. Minimnya guru penjas sehingga berbanding terbalik jumlah siswa yang besar

6. Minimnya pengetahuan siswa terkait teori renang dana pa saja yang harus diperhatikan dalam berenang (Widiastuti dan Hamamah, 2017)

Permasalahan utama dalam pembelajaran ini adalah terkait dengan waktu pembelajaran yang minim disertai pengetahuan yang minim terhadap pteori gerak renang yang meliputi latihan dan pengembangan gerak berenang 
SOLUSI DAN TARGET LUARAN

Permasalahan yang telah dipaparkan, bahwa siswa membutuhkan sarana atau media yang bisa digunakan untuk memperkuat kognitif dalam pembelajaran renang yang diharapkan berimbas kepada keterampilan gerak psikomotorik siswa terhadap pembelajaran ini.

Secara umum dengan adanya media swimcard diharapkan siswa akan mendapatkan:

a. Segi kognitif

- Siswa mempunyai gambran mengenai pembelajaran renang

- Adanya gambar yang bisa dianalisa sehingga tampak nyata dalam pengamatan

- Memperkuat memory siswa untuk mengetahui dan memahami terkait pembelajaran renang

- Adanya kecenderungan untuk bersifat kritis, sehingga siswa bisa memberikan feedback atau masukan bahkan pertnyaan kepada pengajar

- Memacu siswa untuk terus berinovasi terkait pembelajaran dengan adanya contoh media swimcard

b. Segi psikomotorik
- Siswa akan mengetahui apa yang akan dilakukan akrean sudah ada penguatan dari kognitif sebelumnya

- Teknik yang benar cenderung dikuasai karena penguatan dari media swimcard

- Tahapan pembelajaran yang sesuai bisa mereka dapatkan karena mengetahui alur dari media swimcard

\section{Jenis Luaran Yang Dihasilkan}

Jenis luaran yang ditargetkan penulis adalah sebagai berikut:

1) Investasi terkait gerak yang benar dalam pembelajaran renang.

2) Menstimulus siswa untuk hidup aktif dengan aktifitas gerak renang

3) Kesadaran akan pentingnya hidup sehat dan selalu belajar

4) Satu jurnal dipublikasikan pada jurnal nasional

5) Produk media dalam pembelajaran renang yang berkaitan dengan kognitif dan psikomotorik

\section{METODE PELAKSANAAN}

Berdasarkan pembahasan dari bab sebelumnya metode pelaksanaan pengabdian ini dilakukan dengan berproses pada empat macam, yaitu membuat planning, melakukan tindakan, 
mengobservasi dan menilai serta merefleksi

Planning

Yang dilakukan dalam tahapan ini adalah sebagai berikut:

(1) Koordinasi serta meminta izin kepada kepala UPTD di Kecamatan Borobudur.

(2) Memilih sekolah yang akan digunakan untuk tempat pengabdian dengan pertimbangan di sekolah tersebut jauh dari ases dan tidak ada pembelajaran renang.

(3) Memberikan sosioalisasi kepada guru, terutama guru penjas untuk menambah tim yang solid guna memperlancar pengabdian

(4) Menyusun program pengabdian dengan memlih hari, waktu tanggal yang tepat agar sekolah, guru dan siswa tidak merasa terganggu dengan adanya pengabdian

Tindakan

Beberapa hal yang dilakukan adalah sebagai berikut:

(1) Memilih sekolah yang benar benar tepat digunakan untuk pengabdian

(2) Pemberian program pengbdian kepada masyarakat dengan menggunakan media swimcard untuk meningkatkan kemampuan kognitif dan psikomotor siswa sekolah dasar.

Observasi dan Evaluasi

Beberapa hal yang dilakukan dalam tahapan ini adalah dengan melihat secara keseluruhan program pengabdian, mencatat kekurangan dan segera memberi solusi secara responsive atas kekurangan dan memberikan penilaian terhdap hasil yang dicapai dalam pengabdian .

\section{Refleksi}

Sebagai bahan pertimbangan kegiatan pengabdian berikutnya, sehingga pengabdi menyadari akan keterbatasan dari pengabdian yang dilakukan serta mencari solusi atas kekurangan yang ada.

Lokasi pengabdian

Pengabdian ini dilaksankan di slb surya bunda kelurahan wanurejo, kecamatan Borobudur, kabupaten magelang.

\section{HASIL DAN PEMBAHASAN}

Hasil yang kami dapatkan dari tes awal dan tes akhir sangatlah menggembirakan terbukti siswa slb surya bunda meningkat 90 persen dalam hal kognitif. Aspek yang kami lihat dari 
pengamatan selama pengabian sebagai berikut:

1. Sebelum dilaksanakan pre tes kami melakukan apersepsi tentang teknik renang gaya bebas dan hasil yang didapat mereka menjelaskan dari apa yang pernah mereka dapatkan dari otodidak atau berlatih mandiri

2. Hasil dari pretes atau tes awal rata rata siswa mempunyai pemahaman sebanyak 40 persen dari teknik yang efektif dan efisien belajar renang gaya bebas

3. Berikutnya penyampaian metri dengan media swimcard

4. Dan hasil tes akhir atau post tes pemahaman siswa terhadap renang gaya bebas meningkat 90 persen dari hasil yang semula 40 persen.

5. Praktek gerak di darat mereka lebih tahu dengan menerapkan teknik yang benar terutama pada gerak lengan yang harus menggunakan bahu saat posisi recovery, dan saat latihan gerakan tungkai sudut tekuk menjadi lebih minim sehingga tidak menimbulkan hambatan dalam melakukan tendangan tungkai.

Setelah pengabidian ini dilaksanakan terutama jika pandemic sudah berakhir kami berharap dukungannya agar siswa yang sudah diberikan penguatan dalam unsur kognitif belajar gaya bebas dengan menggunakan media swimcard bisa dilanjutkan dengan kegiatan berikunya yaitu latihan praktek unjuk kerja di air.

Berikut grafik perjalanan pengabdian masyarakat

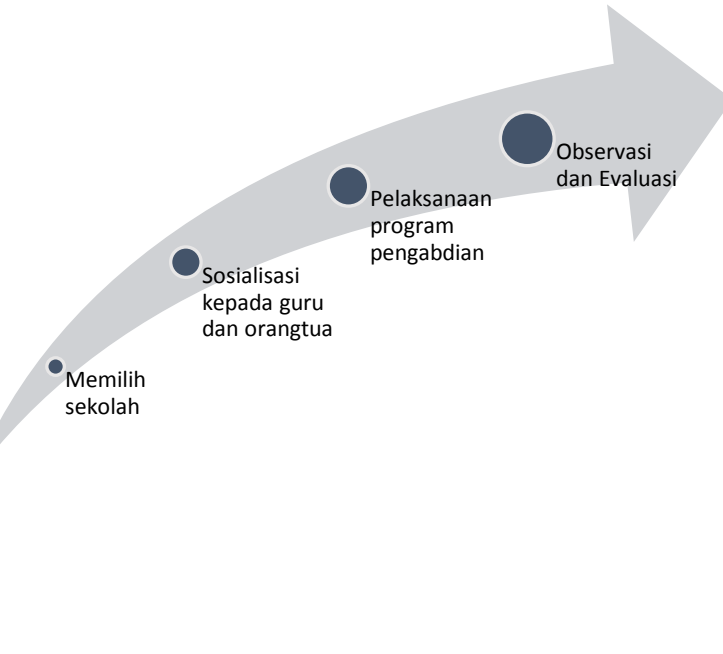

\section{Pembahasan}

Pengabdian berjalan lancar meski di tengah pandemi covid 19 , dari pertama kali datang ke tempat pengabdian kami menerapkan protokol kesehatan seperti yang dianjurkan oleh pemerintah dan unnes, dari jumlah siswa tuna daksa yang berjumlah 4 orang kami optimis bahwa dengan dilaksanakannya pengabdian ini akan mempunyai hasil atau dampak yang nyata terutama dari segi kognitif anak dalam aspek peningkatan pemahaman gerak gaya dalam renang yang efektif dan efisien. 


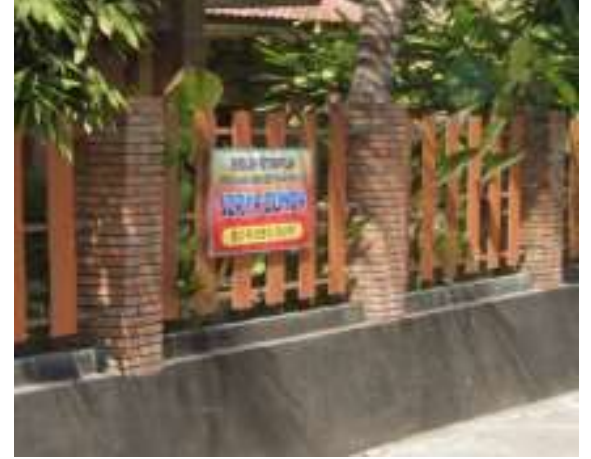

Gambar 1. Lokasi pengabdian

SLB surya bunda sangat kooperatif, dari sisi manajemen sekolah dan gurunya memberikan sambutan yang hangat saat kami datang kesana, setelah beberapa hari yang lalu memberikan izin kami tim pengabdi datang dan segera konsolidasi dengan pihak sekolah terkait pelaksanaan pengabdian, alhasil pengabdian kami secara umum pada tahap pelaksanaan awal berjalan mulus dan tanpa kendala yang berarti.

Siswa tuna daksa sangat antusias menyambut kami, terutama itu diyakinkan oleh guru bahwa setiap ada orang baru datang terutama dalam hal ini dalam artian berkunjung atau bertamu ke SLB surya bunda mereka akan termotifasi karena bukan Cuma kali ini saja mereka dikunjungi. Siswa SLB terutama siswa tuna daksa ingin mengetahui apa yang akan kami lakukan saat pelaksanaan pengabdian nanti, mereka ada yang malumalu tapi beberapa sangat aktif dan bertanya banyak hal dengan tim pengabdi terutama tim yang muda.
Guru slb bercerita tentang sebelum ini pembelajaran yang di lakukan terutama renang sangat terkendala dengan sdm guru, terutama guru penjas yang menguasai keterampilan gerak renang dan mampu menerapkan pembelajaran ini dalam praktek. Sehingga dengan adanya media swimcard ini guru optimis bahwa penguatan dalam hal kognitif akan bisa dilakukan karena mereka berpendapat bahwa pembelajaran aktifitas air atau renang memang perlu terobosan dalam hal inovasi dikarenankan sesuai dengan usia mereka yang sedang bertumbuh dan berkembang.

Sosialisasi yang kami laksanakan di bantu oleh tim pengabdi, sehingga setelah kami di jamu kami dipersilakan untuk segera melaksanakan pengabdian, kami menyiapkan media swimcard dan menata meja dengan jarak 1,5 meter dan setelah itu kami melaksanakan pengabdian dengan diawali pretes mengenai pemahaman renang gaya bebas hasil yang kami peroleh dari pretes rata-rata siswa mendapatkan hasil $40 \%$ dan setelah itu kami memberikan beberapa penguatan terkait materi renang dengan menggunakan swimcard terutama untuk materi yang paling dasar yaitu bagaimana cara belajar berenang gaya bebas bagi pemula, siswa sangat antusias dibuktikan 
saat sesi penjelasan materi ada siswa yang langsung melakukan interupsi bertanya dan di barengi saat pemaparan media mereka mempraktekan tanpa ada aba-aba dari tim pengabdi.

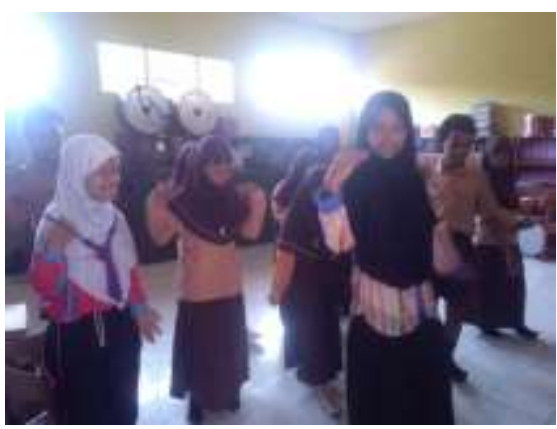

Gambar 2. Susasana sosialisasi di kelas

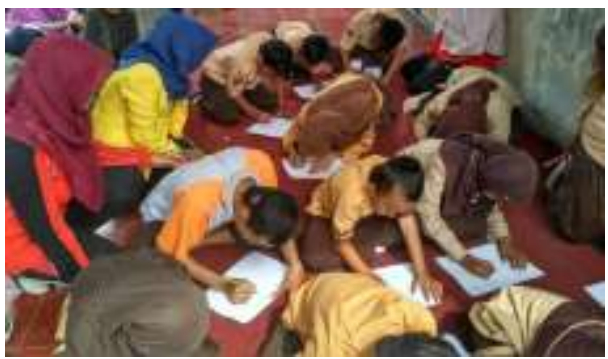

Gambar 3. Suasana saat posttest

Setelah pemaparan selesai kami memberikan feedback, dan setelah itu kami memberikan post tes untuk mengetahui apakah ada peningkatan terkait pemahaman renang gaya bebas, dan ternyata setelah kami koreksi dari pre tes dan post tes ada peningkatan pemahaman dari siswa terbukti mereka menjadi lebih paham dan mengerti tentang teknik gerakan tungkai, gerakan lengan, posisi badan dan pernafasan pada gaya bebas.

Kami bisa akumulasikan pengabdian kami berhasil karena peserta meningkat dalam aspek kognitif sebesar $80 \%$ dari hasil pretes rata-rata $40 \%$, setelah itu pengabdian kami selesai karena pandemi kolam renang masih belum beroperasi dan ditutup, tapi kami merasa puas dengan hasil yang kami raih untuk pengkatan kognitif renang gaya bebas siswa slb surya bunda.

\section{SIMPULAN DAN SARAN}

Simpulan

Program pengabdian kepada masyarakat di slb hendaknya kita tingkatkan, terbukti dengan dilaksanakannya program sosialisasi swimcard di slb surya bunda mempunyai efek yang positif, sebagai berikut:

1) Siswa menjadi lebih antusias dalam belajar pendidikan jasmani terutama materi aktifitas air(renang gaya bebas)

2) Siswa lebih menguasai pemahaman gaya bebas dari segi teknik gerakannya

3) Terobosan inovasi swimcard menjadikan nilai lebih dalam siswa belajar

4) Sebelum terjun kea rah praktek gerakan siswa akan lebih mengetahui arah dan tujuan gerak yang ingin atau akan dicapai

5) Sebagai usaha peningkatan literasi pendidikan jasmani di sekolah 
Saran

Kepada slb surya bunda dan slb yang ada di Indonesia terkhsusus yang mempunyai masalah terhadap pembelajaran gerak renang, saran kami sebagai berikut:

1. Inovasi dibutuhkan dalam rangka memecahkan persoalan pemahaman kognitif peserta didik

2. Senantiasa memperhatikan kebutuhan peserta didik dalam proses pembelajaran

3. Konsistensi bagi para guru untuk terus memberikan bekal hidup bagi siswa slb

4. Mengarahkan kepada NPC Indonesia jika ada peserta didik yang memnag berbakat sehingga bakat yang dimiliki dapat tersalurkan

\section{DAFTAR PUSTAKA}

Arifin B. Pengembangan Gerak Dasar Renang Untuk Anak Sekolah Dasar. J Pemikir Dan Pengemb Sekol Dasar. 2013;

Fathur Rahman, Hj. Silvia Ratna, Wagino Dan NA. Pelatihan Pembuatan Presentasi Interaktif Menggunakan Prezi Pada Guru Di Sd It Anak
Sholeh Mandiri Banjarmasin. J Pengabdi Al-Ikhlas ISSN 24610992 Vol 6 Nomor 2, Desember 2020. 2020;6(9):175-

180Pemanfaatan Media Pembelajaran Seharusnya M.

Rosnawati. Standar Nasional Pendidikan. Peratur Pemerintah Republik Indones. 2005;

Kurnia N, Astuti SI. Peta Gerakan Literasi Digital Di Indonesia: Studi Tentang Pelaku, Ragam Kegiatan, Kelompok Sasaran Dan Mitra Yang Dilakukan Oleh Japelidi. Informasi. 2017;

Eager D. Swimming Faster. Australas Park Leis. 2014;

Leila Ariyani Sofia, Achmad Syamsu Hidayat Dan MAZ. Optimalisasi Media Sosial Sebagai Sarana Promosi Wisata Pantai Asmara. J Pengabdi Al-Ikhlas ISSN 24610992 Vol 5 Nomor 2, April 2020. 2020;5(2):133-43.

Bramantha H. Pengembangan Bahan Ajar Penjaskes Pokok Bahasan Teknik Dasar Renang Gaya Bebas Dengan Pendekatan Kontekstual Pada Siswa Kelas X Di Smk Daerah Situbondo. JPDI (Jurnal Pendidik Dasar Indones. 2017;

WIDIASTUTI W, HAMAMAH F. Model Pembelajaran Renang (Fh) Bagi Siswa Prasekolah. JPUD - J Pendidik Usia Dini. 2017; 